\title{
"I-teach": Processo de Concepção de um Protótipo de Busca e Compartilhamento de Jogos Digitais para Ensino e Aprendizagem de Inglês
}

\author{
Paula Basto Levay ${ }^{1}$, Taciana Pontual Falcão ${ }^{1}$, Rodrigo de Souza \\ ${ }^{1}$ Universidade Federal Rural de Pernambuco (UFRPE) - \\ Rua Dom Manoel de Medeiros, s/n - Dois Irmãos, Recife - PE - Brasil \\ paula_levay@hotmail.com, taciana.pontual@ufrpe.br, \\ pmsrodrigo@gmail.com
}

\begin{abstract}
This article presents the process of designing a prototype of search and sharing of digital games, directed to English teachers. The research was user-centred and carried out in two stages: a brainstorming session and prototyping of interfaces in which 20 teachers participated. The results culminated in the prototyping of a system of search and sharing of digital games for the teaching-learning of English constructed from the needs of the possible users. The system was designed and developed with the purpose of stimulating and facilitating the insertion of digital games in the pedagogical practices of those teachers aiming at the approximation of their practices to the reality of the current students.
\end{abstract}

Resumo.Este artigo apresenta o processo de concepção de um protótipo de sistema de busca e compartilhamento de jogos digitais, destinado a professores de Inglês. A pesquisa foi centrada no usuário e realizada em duas etapas: sessão de brainstorming e prototipação de interfaces, com a participação de 20 professores. Os resultados culminaram na prototipação de um sistema de busca e compartilhamento de jogos digitais para o ensinoaprendizagem de Inglês construído a partir das necessidades dos possíveis usuários. O sistema foi idealizado e desenvolvido com fins de estimular $e$ facilitar a inserção de jogos digitais nas práticas pedagógicas dos docentes visando à aproximação de suas práticas à realidade dos atuais alunos.

\section{Introdução}

Na última década, a difusão rápida de dispositivos móveis na sociedade, especialmente smartphones, ofereceu oportunidades de inovação no processo educacional. Além disso, as tecnologias recentes configuraram uma nova sociedade em que há novas formas de as pessoas se relacionarem e viverem, além de novas maneiras de aprender, adquirir e trocar conhecimento. A realidade educacional nas diversas esferas vive um momento de transformação e readaptação em busca da inserção de novas ferramentas de Tecnologias de Informação e Comunicação (TICs). No entanto, os professores ainda enfrentam dificuldades para introduzir novas práticas e novas ferramentas, seja pela resistência em traçar novos caminhos [Moran 2012] ou pela dificuldade em encontrar tecnologias apropriadas aos seus contextos didáticos. Por outro lado, as novas TICs também proveem uma maior possibilidade de troca, de intercâmbio entre os pares. Esse maior compartilhamento entre professores aumenta a possibilidade de se expandirem práticas 
pedagógicas diferenciadas baseadas na utilização de tecnologias, que podem contribuir para uma melhor qualidade do processo educativo.

No ensino de línguas estrangeiras, os aprendizes precisam entrar em contato com a língua em diferentes contextos, o que, em sala de aula, se configura como uma diversificação de atividades. Essa diversificação é fundamental, sobretudo para crianças em escolas de idiomas, e implica na necessidade de uma variedade de recursos para o professor. Desse modo, proporcionar novas ferramentas, que podem ser utilizadas como material de apoio possibilitará uma maior eficácia no processo de ensino e aprendizagem de Inglês [Motteram 2013].

Entre as práticas pedagógicas diferenciadas, destaca-se o uso de jogos digitais como ferramenta de apoio didático. Partindo desse ponto de vista, pesquisamos recursos tecnológicos nos quais docentes possam buscar e compartilhar jogos digitais apropriados para o ensino de Inglês. Na amplitude deste estudo, não foram encontrados sistemas ou ferramentas em que os professores possam realizar buscas de forma objetiva, rápida e confiável por esses jogos. Desse modo, o objetivo dessa pesquisa foi proporcionar o compartilhamento de conhecimento pelos professores através de um suporte tecnológico para facilitar o processo de inserção de novas práticas pedagógicas e didáticas, como o uso de jogos digitais, em especial por amenizar o problema da falta de conhecimento sobre essas ferramentas, onde encontrá-las e como utilizá-las.

Assim, este artigo apresenta o processo de concepção e desenvolvimento de um protótipo de sistema de busca e compartilhamento de jogos digitais, dirigido a professores de Inglês, como suporte tecnológico para incentivar e facilitar a inserção desses jogos em práticas docentes no processo de ensino-aprendizagem da língua. $\mathrm{O}$ artigo está organizado da seguinte forma: a seção 2 discute a utilização de novas práticas pedagógicas com o apoio de TICs e como dar suporte a professores para que possam adotá-las. A seção 3 descreve a metodologia da pesquisa; a seção 4 apresenta os resultados da pesquisa de campo; a seção 5 explica a ferramenta proposta; e a seção 6 apresenta as conclusões.

\section{Adoção de Novas Práticas Pedagógicas}

Vivemos em uma sociedade de aprendizes digitais. "Os nativos digitais são os jovens de hoje em dia que sempre tiveram contato com a tecnologia" [Toshi 2010, p.8]. Os novos estilos de aprendizes são o resultado das grandes transformações, especialmente tecnológicas, pelas quais a sociedade passa. Então, configurou-se uma nova sociedade, cada vez mais conectada e que "exige dos educadores e dos educandos uma aprendizagem baseada na coletividade e nas trocas interativas" [Marques 2014, p.61]. Ou seja, a sociedade mudou e os papéis da escola precisam seguir a mesma direção.

Para haver mudanças estruturais na educação, Moran (2012) defende que a peçachave está na figura do professor. Os professores precisam refletir acerca da dinâmica atual das escolas e das aulas. De acordo com Moran (2012) as tecnologias promovem mudanças. Entende-se, então, que novas tecnologias podem ser alternativas viáveis para se inovar as práticas. Para Marques (2014) as tecnologias não resolverão os problemas relacionados ao fazer pedagógico, entretanto, elas podem ser um caminho mais rápido de aproximação com os jovens.

Segundo Kenski (2007), a escolha do tipo de tecnologia altera imensamente a natureza do processo educacional. Algumas novas tecnologias estão em consonância com os estilos dos nativos digitais e os docentes precisam organizar suas aulas de modo mais interativo e motivador [Prensky 2009]. Para isso, eles precisam "ouvir" os nativos 
VI Congresso Brasileiro de Informática na Educação (CBIE 2017)

Anais do XXIII Workshop de Informática na Escola (WIE 2017)

digitais e adotar as tecnologias com as quais esses têm afinidade. Entre essas tecnologias, destacam-se os jogos digitais, artefatos próximos do contexto dos atuais aprendizes. Jogos digitais podem trazer diversos benefícios para processos de aprendizagem e desenvolvimento de habilidades [Felicia 2012; Silva et al. 2016; Mello e Dantas 2015].

De particular interesse para o foco desta pesquisa são as evidências de que esses jogos podem contribuir substancialmente para a aprendizagem de Língua Inglesa [Motteram 2013]. Trabalhos relacionados ao tema apontam algumas contribuições dos jogos para aquisição de vocabulário em Inglês [Uzun 2009; Chen e Yang 2013; Ruphina e Liu 2011]. Uma pesquisa anterior dos autores conduzida com crianças entre 4 e 6 anos [Levay et al 2015] mostra contribuições dos jogos digitais para revisitação e assimilação de vocábulos e aumento do interesse em participar da aula. Outro trabalho dos autores mostra que tarefas sugeridas por jogos digitais podem contribuir para que os alunos/jogadores desenvolvam o pensamento crítico através de atividades de raciocínio lógico [Levay et al 2015].

Apesar das várias contribuições e oportunidades que novas tecnologias podem oferecer à aprendizagem, ainda existem resistências e dificuldades para sua inserção em vários contextos educacionais. Por outro lado, Massaro (2014) aponta que o conhecimento de como utilizar novos materiais pode e deve ser dividido e compartilhado com os demais professores. Algumas pesquisas e estudos realizados recentemente mostram que a colaboração entre os professores pode ser uma ferramenta poderosa para o desenvolvimento profissional e um veículo para a melhoria da escola [Mcclure 2008]. No entanto, muitas vezes a colaboração entre pares se torna difícil pela falta de tempo dos docentes em se encontrar presencialmente para troca. Nesse sentido, ferramentas tecnológicas podem facilitar esse intercâmbio. Para alguns autores, a popularização do uso do microcomputador, na década de 1980, é o ponto de partida para disseminação crescente de informação dentro da sociedade. Ou seja, a expansão do conhecimento pode estar ligada a recursos tecnológicos que facilitam a dinâmica de dar e receber informações. Schiehl et al. (2012) defendem que os professores devem ser conduzidos a fazer trocas constantes de experiências, de forma a promover uma melhoria contínua na prática docente, e compartilhar não apenas experiências, mas também materiais, o que pode contribuir para a otimização de seu tempo. Os autores postulam que, pelas dificuldades de tempo e localização, é relevante o desenvolvimento de ferramentas que possibilitem a interação entre a comunidade educacional. De acordo com Massaro (2014), as redes colaborativas favorecem o envolvimento de todos os sujeitos no processo de criação de materiais educacionais e na construção do conhecimento, possibilitando a multiplicação do saber e as inovações nos processos educativos.

Indo ao encontro das ideias supracitadas, o presente estudo pretende oferecer um suporte tecnológico que possa contribuir para o compartilhamento de jogos digitais por professores de Inglês, facilitando, dessa forma, o intercâmbio e consequente uso dessa ferramenta em práticas pedagógicas. Consideramos que a quantidade de sistemas de busca, compartilhamento e armazenamento encontrados ao longo de nossa pesquisa evidencia que esses suportes digitais podem ser meios para disseminar conhecimento, ideias e materiais entre pares. Ao mesmo tempo, essa busca e análise dos sistemas já existentes nos permitiu identificar dificuldades para encontrar jogos digitais, sobretudo de forma prática, objetiva e que otimize o tempo do professor. Permitiu-nos também visualizar oportunidades para inovações dos sistemas existentes. 
VI Congresso Brasileiro de Informática na Educação (CBIE 2017)

Anais do XXIII Workshop de Informática na Escola (WIE 2017)

\section{Metodologia}

Para a concepção do suporte tecnológico de busca e compartilhamento de jogos digitais para professores de Inglês, foi realizada uma pesquisa de abordagem qualitativa centrada no usuário [Barbosa e Silva 2010] com 20 professores de Inglês de uma escola de idiomas localizada na cidade de Recife, Pernambuco. Esses professores realizam rotineiramente atividades para o quadro digital utilizado na escola, estando, portanto, familiarizados com o uso de tecnologia em sala de aula. Além disso, apesar de existirem diferenças de faixa etária, o grupo de professores apresenta, sobretudo, uma característica homogênea quanto à metodologia adotada em suas práticas pedagógicas. A metodologia da escola baseia-se em uma dinâmica de aulas em que há diversificação de atividades, o que requer desses profissionais fazer uso e preparar diferentes materiais. A pesquisa foi realizada em duas etapas: sessão de brainstorming e prototipação.

$\mathrm{Na}$ primeira etapa, buscamos verificar quais as necessidades específicas dos professores em relação a um suporte tecnológico para que possam utilizar mais jogos digitais ou que facilite a inserção desses jogos em suas práticas pedagógicas. Essas necessidades foram coletadas através da técnica de brainstorming (tempestade de ideias) [Barbosa e Silva 2010], gravada em áudio, que durou uma hora. A sessão foi conduzida pela primeira autora deste artigo. Nesta sessão de brainstorming, os professores mencionaram funcionalidades e características para o sistema, as quais foram concretizadas na segunda etapa, que consistiu em uma sessão de prototipação em papel [Snyder 2003] com os docentes, para desenhar as possíveis interfaces e características do sistema proposto. Os professores foram divididos em grupos e construíram oito protótipos de baixa fidelidade em papel. Ao final dessas etapas, foi construído um protótipo digital agregando as ideias e sugestões e as materializando em um produto final.

\section{Resultados}

\subsection{Resultados da Sessão de Brainstorming}

A Figura 1 mostra alguns registros da audiogravação da sessão de brainstorm. Para apresentação dos resultados da audiogravação, serão apontadas algumas falas dos professores. Os professores são identificados com P1, P2, sucessivamente.

P1: Eu gostaria de ter uma rede colaborativa ou um aplicativo que me dissesse que músicas os alunos estão gostando, dependendo da faixa etária.

P2: Uma coisa que surgiu esse semestre pra mim é que muitos de nós temos as mesmas turmas, a gente prepara aulas diferentes, então queria um site interno com nomes e telefones dos professores, com as aulas salvas e títulos padrão e que os professores pudessem se encontrar online.

P3: Tudo gira para uma coisa muito forte que é sharing (compartilhamento) de aulas, materiais, songs, planejamento online.

P4: uma plataforma com links que já foram utilizados, que já prestaram, pelo menos pedagogicamente falando, nela pode haver uma busca por nível da turma, ou por livro, um perfil para cada usuário, descrição dos jogos.

P5: atividades com tags, um espaço para o usuário registrar, primeiramente para não esquecer e também para sugerir e a partir dessa colaboração, ser criado um filtro selecionado e não repetitivo, de jogos testados para não perder tempo, opção de colocar um comentário.

Figura 1. Registros da audiogravação na sessão de brainstorming 
Os resultados mostram que os professores consideram que existe a possibilidade de busca por jogos e outras atividades na Internet, mas que essa busca é muito geral, ou seja, que os sistemas de recomendação subjacentes às ferramentas de busca tradicionais não atendem satisfatoriamente ao nível de especificidade necessário para a escolha de uma ferramenta educacional adequada, de acordo com os requisitos pedagógicos que fazem parte da prática docente. Assim, os possíveis usuários sentem a necessidade de obter uma ferramenta ou um produto de busca específico, o qual colaboraria para otimizar o tempo de busca, com um filtro, com jogos indicados por profissionais da área que realmente utilizaram os jogos ou as atividades sugeridas e que puderam avaliar se funcionam. Além disso, devido à quantidade de opções na internet e por não haver um ambiente específico para busca e registro, muitas vezes os professores utilizam um jogo e esquecem posteriormente, não podendo, então, utilizá-lo novamente ou compartilhá-lo com outros professores.

\subsection{Resultados da Etapa de Prototipação de Interfaces}

$\mathrm{Na}$ etapa de prototipação, os professores desenharam sugestões de interfaces para o sistema, de acordo com as ideias geradas no brainstorming. Os docentes puderam indicar livremente itens, sem haver direcionamento por parte da pesquisadora. Em grupos, eles construíram 8 protótipos. As figuras 2 e 3 mostram exemplos de algumas sugestões indicadas nos protótipos, como filtros por categorias (idade, tópico, nível) (Figura 2) e seção de busca (Figura 3).

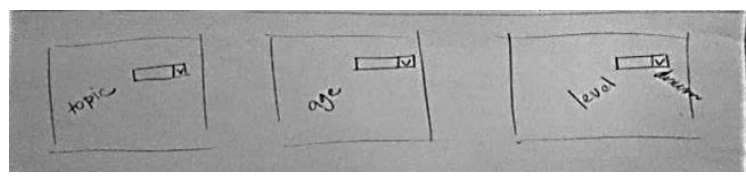

Figura 2. Exemplo de protótipo com sugestão de filtros por categorias

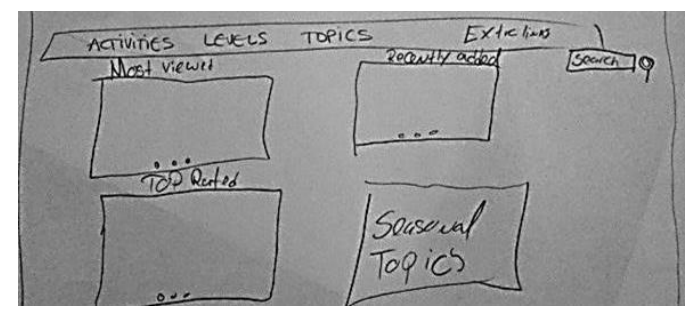

Figura 3. Exemplo de protótipo com sugestão de seção de busca

As características da interface e as funcionalidades do sistema sugeridas pelos professores, e o número de professores que as sugeriram, foram compiladas na Tabela 1.

Tabela 1- Características da interface do sistema sugeridas pelos professores nos
protótipos
\begin{tabular}{|l|c|}
\hline Item & Número de participantes que citaram \\
\hline $\begin{array}{l}\text { Interface com subtópicos (para evitar muitas informações na } \\
\text { mesma tela) }\end{array}$ & 17 \\
\hline Avaliação com estrelas & 8 \\
\hline Avaliação com comentários & 3 \\
\hline
\end{tabular}


VI Congresso Brasileiro de Informática na Educação (CBIE 2017)

Anais do XXIII Workshop de Informática na Escola (WIE 2017)

\begin{tabular}{|l|c|}
\hline Descrição dos jogos em subtópicos & 7 \\
\hline Site em formato de listas & 1 \\
\hline Descrição dos jogos em tags & 1 \\
\hline Seçãoparabusca & 9 \\
\hline Filtro por idade do público-alvo & 16 \\
\hline Filtroporvocabulário & 12 \\
\hline Filtroporpontosgramaticais & 8 \\
\hline Descrição dos jogos & 8 \\
\hline Indicação de jogos mais populares & 7 \\
\hline Indicação de últimaspostagens & 6 \\
\hline
\end{tabular}

Além de a sessão de brainstorming e a etapa de prototipação terem permitido obter algumas características do sistema e necessidades dos possíveis usuários, essas duas etapas da pesquisa foram fundamentais, também, para justificar a criação do produto, tendo em vista as colocações dos professores participantes que ratificaram algumas características pensadas para o produto, como busca selecionada, objetiva e rápida. Durante a sessão, os professores ratificaram a ausência de ferramentas para esse tipo de busca e também registro. A partir das sugestões apontadas nos protótipos, foi concebida uma proposta de sistema, agregando as várias ideias.

\section{Proposta de Ferramenta: Sistema I-teach}

A ferramenta I-teach foi desenvolvida a partir das funcionalidades e características propostas pelos docentes participantes da pesquisa, que são usuários típicos desse sistema. Como já exposto nos resultados da sessão de brainstorming, os professores apresentaram necessidades além das previamente visualizadas no início dessa pesquisa. Eles propuseram que o sistema fornecesse jogos digitais para diversas faixas etárias, não somente para crianças pequenas. $\mathrm{O}$ sistema foi, então, desenvolvido com a possibilidade de busca por diferentes faixas etárias. Além disso, os professores sugeriram que o sistema pudesse fornecer ideias de músicas, atividades e planos de aulas, além dos jogos. Esta é uma possibilidade de trabalhos futuros de expansão do sistema.

O sistema é um website implementado utilizando a linguagem ClosureTemplates, desenvolvida pelo Google. A escolha desta tecnologia foi feita por ela permitir que tanto a aplicação no servidor quanto a aplicação no cliente (o navegador) sejam capazes de interpretar os templates nela escritos - o que evita duplicação e facilita a manutenção do código. Os templates escritos nesta linguagem estão sendo utilizados para gerar o markup HTML do sistema. Para disposição do layout e definições visuais, foi utilizado CSS. A aplicação no cliente foi escrita em JavaScript e usa jQuery com framework base.

I-teach fornece um espaço no qual as buscas por jogos são feitas de forma objetiva, rápida e organizada, podendo filtrar por categorias como: faixa etária, vocabulário, pontos gramaticais e sistema operacional. Na página inicial do sistema, foram colocadas algumas das características sugeridas nas sessões de brainstorming e prototipação, como filtros por categorias, seção para busca e layout com subtópicos. A Figura 4 mostra a tela inicial. 


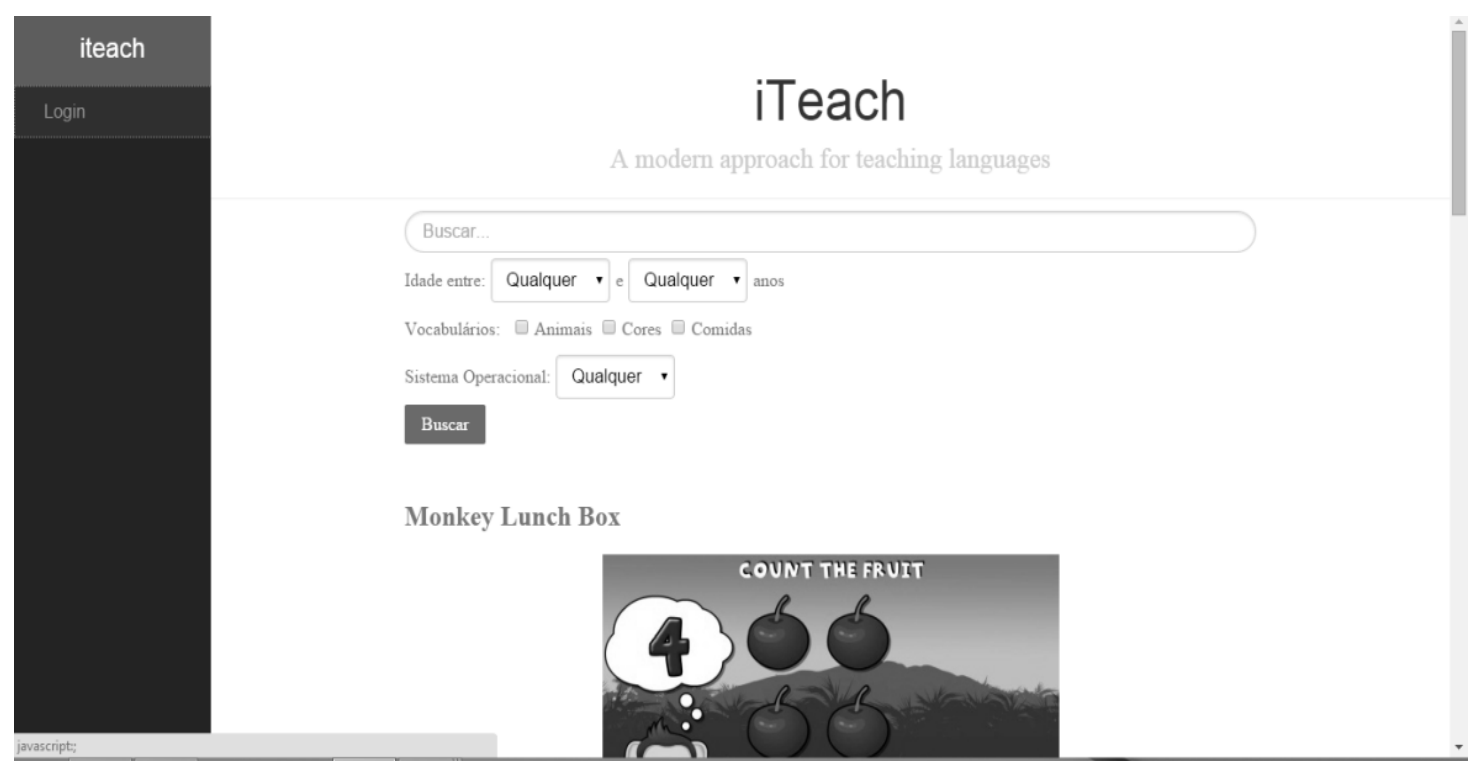

Figura 4. Tela inicial do sistema

Esta tela possui uma rolagem e alguns exemplos de jogos que o sistema contém. Para cada jogo, existe a descrição na qual os usuários podem encontrar informações referentes às atividades presentes nos jogos, as contribuições cognitivas que os jogos podem oferecer, além das imagens de algumas telas dos jogos. A ideia de exibir as telas dos jogos surge a partir da necessidade de os professores obterem o máximo de informações possíveis acerca do jogo para adequação precisa às suas necessidades. Com as telas e a descrição, o professor possivelmente saberá exatamente o que o jogo oferece e as atividades que os alunos deverão realizar ao jogar. Essa funcionalidade poderá contribuir para que o professor/usuário não gaste muito tempo procurando.

Além disso, o sistema pode ser considerado um sistema personalizado no qual os usuários criam um perfil e são sugeridos jogos e novidades a partir das características fornecidas nas informações de perfil. O professor fará um cadastro e responderá algumas perguntas para que o sistema obtenha informações para fazer recomendações ao usuário. No login, o sistema sugerirá novos jogos indicados para os níveis que o professor ensina e o público-alvo com o qual serão utilizados. Nesse sentido, o sistema I-teach fornece sugestões de jogos previamente analisados para diversas faixas etárias, além de temas e sistemas operacionais nos quais os jogos podem ser encontrados.

Os jogos listados no sistema serão inicialmente inseridos por um especialista, porém a ideia é que os próprios usuários passem a colaborar para a formação de uma coleção rica de jogos. Para isso, o sistema apresenta uma ferramenta colaborativa na qual os professores podem sugerir jogos que ainda não estão listados. Essa característica também provê a possibilidade de registro para que o professor não esqueça um jogo que utilizou e gostou. Um ou mais moderadores serão responsáveis por analisar e selecionar os jogos sugeridos pelos usuários. A ideia é que os moderadores sejam professores de Inglês com experiência com jogos digitais, tornando o sistema confiável. Essa hierarquização de usuários é também uma proposta do sistema de recomendação que estamos apresentando.

A Figura 5 mostra a tela do sistema quando o moderador faz o login com sua senha. Nesta interface, há parâmetros que devem ser utilizados na análise dos jogos pelo moderador. Os parâmetros para análise estão na parte esquerda da tela e os jogos sugeridos pelos usuários 
na parte superior com a mensagem: 'Olá, moderador, você tem 2 jogos para serem revisados'. Esses parâmetros foram definidos a partir de uma análise de estudos da área de ensino de Inglês e interface de jogos digitais para crianças [Felicia 2012; Peirce 2013].
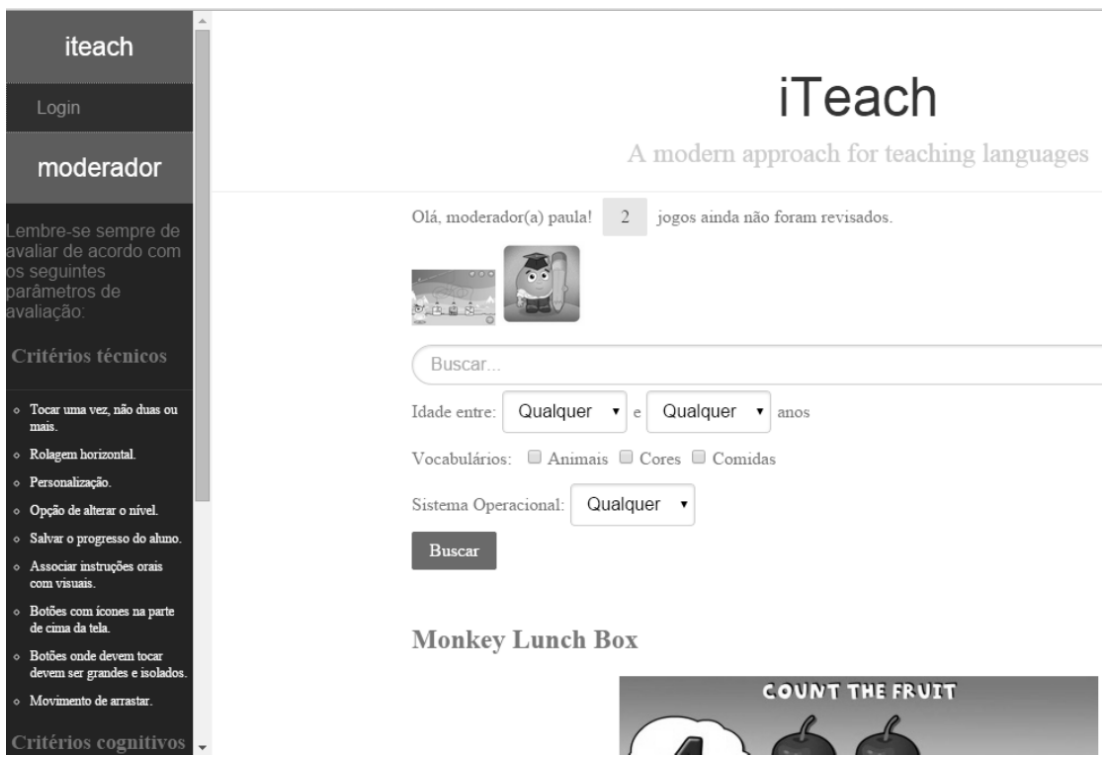

Figura 5. Tela do sistema quando feito o login do moderador

É relevante destacar que se o sistema atingir um público grande a proposta é torná-lo sustentável, através da colaboração dos usuários, agindo como avaliadores dos jogos de modo que a avaliação não fique centralizada apenas no papel do moderador. As políticas de eleição de moderadores são uma discussão para trabalhos futuros em um eventual contexto de popularização.

\section{Considerações Finais}

$\mathrm{O}$ estudo apresentado neste artigo evidenciou a dificuldade na busca de jogos digitais adequados para ensinar e aprender Inglês. Constatou-se que os professores gostariam de obter um recurso tecnológico especializado e prático para buscas por jogos digitais e mais centrado nos seus perfis e necessidades enquanto usuários.

O sistema proposto neste trabalho leva em consideração tais pressupostos visando oferecer uma ferramenta que responda melhor às necessidades dos possíveis usuários, sendo confiável, objetiva e que consequentemente otimize o tempo de busca, já que permite encontrar especificamente jogos digitais para ensino-aprendizagem de Inglês, avaliados por um moderador profissional da área. Consideramos que o sistema construído, no qual os professores possam realizar buscas, filtrando por categorias desejadas, e sugerir (e consequentemente registrar) jogos que utilizaram e gostaram, poderá facilitar a busca por jogos digitais e a consequente utilização desses jogos. Além disso, acreditamos que facilitará o compartilhamento de jogos entre os professores, e consequentemente poderá haver um número maior de opções de jogos para serem usados nas aulas de Inglês.

Trabalhos futuros decorrentes desse estudo visam realizar testes de usabilidade com professores de Inglês para verificar a experiência de uso e aceitação do sistema. Esse teste pode provocar ajustes e extensões no protótipo. Indica-se, ainda, um estudo mais longo em que alguns professores sejam conduzidos a utilizar o sistema por um período e seja realizada uma análise para verificar se, fazendo uso do sistema, os professores encontrariam mais 
VI Congresso Brasileiro de Informática na Educação (CBIE 2017)

Anais do XXIII Workshop de Informática na Escola (WIE 2017)

facilmente jogos digitais e, por isso, utilizariam mais frequentemente esses jogos em suas práticas docentes.

\section{Referências}

Barbosa, S.; Silva, B. (2010) “Interação humano-computador”. Rio de Janeiro: Elsevier.

Chen, H.; Yang, C. (2013) "The impact of adventure video games on foreign language learning and the perceptions of learners".Interactive Learning Environments. V. 21, n. 2.

Felicia, P. (2012) "Digital Games in schools: a handbook for teachers. EuropeanSchoolnet"

Kenski, V.M. (2007) "Educação e tecnologias: o novo ritmo da informação”. São Paulo: Papirus.

Levay, P.; Pontual Falcão, T.; Diniz, J. Souza, R.(2015)“Uma experiência de uso de jogos digitais como ferramenta de apoio para aprendizagem de Inglês por crianças". Anais do XXI Workshop de Informática na escola.

Marques, R. (2014) "Letramento Digital na Ciberinfância: diálogos com práticas pedagógicas no Ensino Fundamental". Dissertação de Mestrado. Departamento de Educação a Distância, UFRPE. Garanhuns.

Massaro, G. (2014) "Recursos educacionais abertos e aprendizagem colaborativa: novas perspectivas na construção e utilização de materiais educacionais”. Colabor@ - Revista Digital da CVA - Volume 8, Número 31.

Mattar, J. (2009) “Games em educação: como os nativos digitais aprendem”1ed.São Paulo: Pearson Prentice Hall.

Mello, T.S; Dantas, A. (2015) "GameMaking: Uma Metodologia para o Ensino de Informática para Alunos do Ensino Fundamental através da criação de Jogos Digitais". Revista Brasileira de Informática na Educação, Volume 23, Número 1.

Moran, J. M. (2012) “A educação que desejamos: novos desafios e como chegar lá”. 5 ed. Campinas: Papirus.

Mcclure, C. (2008) “The Benefits of teacher collaboration”. District Administration, sep,

Motteram, G. (org) (2013) "Innovations in learning for English language teaching”. British Council.

Neto, J.; Fonseca, F. (2013) "Jogos educativos em dispositivos móveis como auxílio ao ensino da Matemática”. Novas Tecnologias na Educação, V. 11 № 1. CINTED-UFRGS.

Peirce, N. (2013) "Digital Game-Based Learning for earlychildhood". Learnovate Centre,

Prensky, M. (2001) "Digital Natives, digital immigrants". On the Horizon.

Ruphina, A.; Liu, M. (2011) "Digital games: Potential Integration of Mingoville games in Learning English as a Foreign Language".Proceedings of Society for Information Technology \& Teacher Education International Conference , (pp. 2216-2222).

Schiehl, E.; Matos, A.; Gasparini, I.; Kemczinski, A. (2012) "Compartilhamento de experiências docentes através de uma ferramenta para uma rede social".IV Workshop sobre Aspectos da Interação Humano-Computador para a Web Social,.p. 29-38.

Silva, T.; Aranha, E.; Fernandes, K.; Santos, F. (2016) "Um relato de experiência da aplicação de videoaulas de programação de jogos digitais para alunos da educação básica". Anais do XXII Workshop de Informática na Escola, WIE-2016. 
VI Congresso Brasileiro de Informática na Educação (CBIE 2017)

Anais do XXIII Workshop de Informática na Escola (WIE 2017)

Snyder, C. (2003) "Paper prototyping: the fast and easy way to design and refine user interfaces".Morgan KauffmanPublishers.

Toshi, M.S. (org) (2010)“Leitura na tela, da mesmice à inovação”. 1 ed., Goiânia: Editora da PUC- GO,180p.

Uzun, L. (2009) "An evaluative checklist for computer games used for foreign language vocabulary learning and practice: vocaword sample.”Novitas-ROYAL, Vol. 3 Issue 1, p45-59. 